\title{
Drugs to cure avian influenza infection - multiple ways to prevent cell death
}

S Yuan ${ }^{\star 1}$

New treatments and new drugs for avian influenza virus (AIV) infection are developed continually, but there are still high mortality rates. The main reason may be that not all cell death pathways induced by AIV were blocked by the current therapies. In this review, drugs for AIV and associated acute respiratory distress syndrome (ARDS) are summarized. The roles of antioxidant (vitamin C) and multiple immunomodulators (such as Celecoxib, Mesalazine and Eritoran) are discussed. The clinical care of ARDS may result in ischemia reperfusion injury to poorly ventilated alveolar cells. Cyclosporin A should effectively inhibit this kind of damages and, therefore, may be the key drug for the survival of patients with virus-induced ARDS. Treatment with protease inhibitor Ulinastatin could also protect lysosome integrity after the infection. Through these analyses, a large drug combination is proposed, which may hypothetically greatly reduce the mortality rate.

Cell Death and Disease (2013) 4, e835; doi:10.1038/cddis.2013.367; published online 3 October 2013

Subject Category: Immunity

\section{Facts}

- The infection of avian influenza induces reactive oxygen species accumulation, causing hyperimmune response to the virus, which may have adverse effects on vital organs and result in high pathogenicity and mortality.

- Clinical care of acute respiratory distress syndrome may result in ischemia reperfusion injury to alveolar cells that are poorly ventilated or poorly supplied with blood. The main mechanism includes mitochondrial permeability transition and the release of apoptotic mediators.

- Combinations of immunomodulators and antiviral agents significantly reduced mortality in mice infected with the avian influenza virus (AIV). However, the reduced mortality rate was still relatively high (over 10\%).

- Virus neuraminidase digests lysosomal membrane glycoproteins, which induces lysosome lysis and the release of lysosomal proteases. This is another mechanism of AIVinduced cell death.

\section{Open Questions}

- New treatments and new drugs for avian influenza are developed continually; then why is there still such a high mortality rate?

- Why did acute respiratory distress syndrome clinical cares enable the survival of only partially AIV-infected patients, whereas the others died?
- Can immunomodulators and antiviral agents completely cure AIV infection?

- Is there a hope of reducing the mortality rate to below $1 \%$ (as is the case of the ordinary influenza)?

Over the last decade, an endless stream of severe acute respiratory syndrome (SARS), influenza ( $\mathrm{H} 1 \mathrm{~N} 1, \mathrm{H} 5 \mathrm{~N} 1, \mathrm{H} 7 \mathrm{~N} 9$ ) and associated malignant respiratory diseases have emerged, which threatens the human health seriously. Because of their high mortality rate and infectious nature, these diseases usually cause psychological panic among the public that is more serious than the diseases themselves. As reported on 10 May 2013, of the 111 patients we studied $76.6 \%$ were admitted to an intensive care unit and $27.0 \%$ died. ${ }^{1}$ New treatments and new drugs for avian influenza are developed continually, then why is there such a high mortality rate? We have to introspect about our current therapies for avian influenza and develop a better one. In this review, therapeutic uses of the drugs for avian influenza and associated pneumonia are summarized. In general, conventional therapies using only antiviral drugs resulted in $50-80 \%$ mortality rate, whereas the new therapies with antiviral drugs and immunomodulators reduced the mortality rate to $10-50 \%$. However, this was still a high ratio. The main reason may be that not all cell death pathways induced by the AIV were blocked by the therapies (Figure 1). At the end of this review, a large reagent combination is proposed, which may greatly reduce the mortality rate prospectively.

\footnotetext{
${ }^{1}$ College of Resources and Environmental Sciences, Sichuan Agricultural University, Chengdu, China

${ }^{*}$ Corresponding author: S Yuan, College of Resources and Environmental Sciences, Sichuan Agricultural University, Chengdu 611130, China; Tel: + 86 28 86291325 ; Fax: + 86028 86290983; E-mail: roundtree318@ @otmail.com

Keywords: avian influenza virus infection; acute respiratory distress syndrome; cell death; combination therapy; reactive oxygen species

Abbreviations: AICT, avian influenza cocktail therapy; AIV, avian influenza virus; ARDS, acute respiratory distress syndrome; Bax, Bcl-2-associated X protein; Bcl-2, B-cell lymphoma 2; CsA, cyclosporin A; HPV, hypoxic pulmonary vasoconstriction; IFN, interferon; IL, interleukin; IR, ischemia reperfusion; mPT, mitochondrial permeability transition; NA, neuraminidase; NF-AT, T-cell-specific transcription factor; NF-IL-2A, IL-2 promoter element; ROS, reactive oxygen species; SARS, severe acute respiratory syndrome; TLR4, Toll-like receptor 4; TNF $\alpha$, tumor necrosis factor- $\alpha$; VC, vitamin C

Received 24.6.13; revised 15.8.13; accepted 16.8.13; Edited by A Stephanou
} 

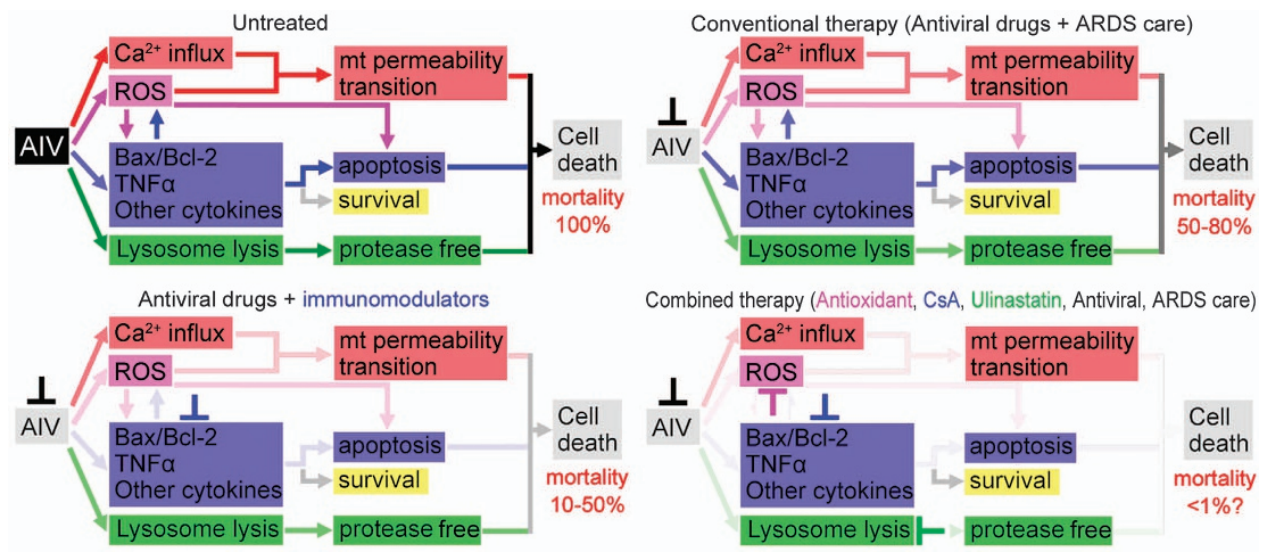

Figure 1 Summary of therapies, mortality rates and the therapeutic mechanisms. AIV, avian influenza virus; ARDS, acute respiratory distress syndrome; $\mathrm{mt}$, mitochondrion; ROS, reactive oxygen species; CsA, cyclosporin A

The symptoms of H7N9 infection, that is, the upper respiratory tract infection, is not very heavy with mild cough, which does not attach attention to the majority of the patients. However, the disease progresses very quickly. Ten days post infection, pulmonary symptom appears immediately (pneumophila). Next, the condition involves the proliferation of both lungs, serious lung exudation and low pulmonary oxygenation (low oxygenated blood). A patient without effective treatments at that time will develop acute respiratory distress syndrome (ARDS) and may die a few days later. ${ }^{2}$ Symptoms of other types of avian influenza and SARS are almost the same. Hence, the key to survival of the patients may be not only the suppression of the virus but also the controlled inflammatory response of the hosts.

The SARS mortality statistics published by World Health Organization in 2003 showed that the overall average mortality rate was about $15 \%$, but the mortality rate of young people with strong immunity was much higher than that of old people with weak immunity. ${ }^{3}$ For H5N1, the overall mortality rate was about $56 \%$. However, the youth group (10-19 years old individuals) got the highest mortality rate of $73 \%$ and the mortality rate for people over 50 years was only $18 \%{ }^{4}$ Moreover, $\mathrm{H} 1 \mathrm{~N} 1$ deaths mostly occur in middle-aged adults and the severity of the $\mathrm{H} 1 \mathrm{~N} 1$ cases was by far higher in the 18-50 years age group, contrary to seasonal influenza where fatal disease occurs most often in the elderly people ( $>65$ years old), with an overall mortality rate being $<1 \%{ }^{5}$ Some researchers believe that the infection of avian influenza causes multiple complications in the patient, resulting in multiorgan failure, and may be related to the hyperimmune response to the virus, which may have adverse effects on vital organs and result in high pathogenicity and mortality. ${ }^{6-9}$ The H5N1 virus may set off a cytokine storm, for example, interferon (IFN)-inducible protein IP-10, IFN- $\beta$, chemokines, interleukin-6 (IL-6) and so on. This cytokine outbreak is likely to lead to cell death. ${ }^{6-9}$ These data may suggest that healthy young people would become the main target of $\mathrm{H} 5 \mathrm{~N} 1$ attack. In other words, the stronger the immune system, the more severe the inflammatory response after the infection and, thus, the higher risk of death. AIV does not kill us, but we may be killed by ourselves. For the newborn virus H7N9, no such full-scale statistics is available now. Nevertheless, from its high mortality rate and rapid disease progression, ${ }^{1,2}$ a similar cytokine burst with an excessive immune response can be expected (cytokine burst in the H7N9 patient has been proved recently). ${ }^{10,11}$

\section{Antioxidant}

Reactive oxygen species (ROS) have a crucial role in inflammatory response. ${ }^{12}$ Aggregation of neutrophils at pulmonary alveoli activate and release the oxygen-free radicals, proteases and lipid peroxide, resulting in injuries to the pulmonary microvascular membrane and alveolar epithelial membrane, and the subsequent pulmonary edema and ARDS. The activated neutrophils generate ROS exponentially (over 10 times the rate in the resting cell). The oxidative injuries include the following: (i) lipid peroxidation and detriments to structures and functions of the cell membrane and the organelle membrane; (ii) enzyme inactivation; (iii) inactivation of protease inhibitors and release of lysosomal proteases; and (iv) working on blood plasma to induce strong chemoattractants, causing more neutrophil aggregation, more ROS production and subsequently more severe lung injury. ${ }^{12}$ Thus, ROS form a positive feedback loop (they could be self-amplified).

Among all ROS scavengers, ascorbic acid (vitamin C (VC)) is the best choice, as it is effective, non-toxic, easy to be absorbed and more stable than the others (similar to reduced glutathione). VC scavenges ROS through a non-enzymatic process. ${ }^{13}$ In the ninteenth century, VC had been used to treat hepatitis, encephalitis, influenza, SARS and some other viral diseases. ${ }^{13}$ In 1970, Nobel laureate chemist Linus Pauling published the book 'Vitamin C And The Common Cold', wherein he advocated that high doses of VC can prevent and treat colds. ${ }^{14}$

There is little direct evidence to show that the high amounts of VC would be helpful for patients during a severe avian influenza infection. However, an investigation showed that in several publicized locations, including Vietnam, many (about $50 \%$ ) of the humans infected with avian flu (H5N1) did not die. ${ }^{15}$ Ely ${ }^{16}$ suggested that their survival may have occurred, as the particular viral load constituting their moderate infection may have been small enough that the 
VC they accidentally acquired from their diets was adequate to defend them.

There are about 4000 species of 'normal' mammals that synthesize $\mathrm{VC}$, on average $\sim 50 \mathrm{mg} / \mathrm{kg}$ body weight daily or about $5 \mathrm{~g} /$ day (normalized to $70 \mathrm{~kg}$ for a human). ${ }^{16,17}$ This amount has been found to be essential for optimum health and resistance to many diseases. ${ }^{13,14}$ In summary, from a large number of studies, ${ }^{13-17}$ we know that effective inhibition of viral replication and apparent symptom alleviation usually requires over $5 \mathrm{mM}$ of $\mathrm{VC}$ (about $4.4 \mathrm{~g}$ for about $5 \mathrm{I}$ of human blood). However, the general oral dosage of VC tablets is 100-300 mg daily, which is much lower than the dose required for influenza treatment. For higher absorption efficiency, and considering that over $1 \mathrm{~g}$ of VC by oral administration may cause diarrhea, nausea, vomiting, stomach cramps and other side effects, ${ }^{13-17}$ the injection approach could be adopted for those patients infected with avian influenza. In addition, longterm use of high-dose VC ( $>2-3 \mathrm{~g} /$ day) causes scurvy after abrupt stopping. Thus, the VC injection should be reduced gradually during recovery but not stopped abruptly. ${ }^{13-17}$

When most patients were identified to be infected by AIV and have been sick for a couple of days, pulmonary symptoms started to develop. Their alveolar cells may be already damaged. Therefore, their risks to develop acute respiratory failure were very high. Timely pretreatment with VC before diagnosis in the hospital may be very important for the patient to avoid lethal inflammation. ${ }^{13-17}$

\section{Protectant of Mitochondrial Membrane Permeability}

Simply providing humans with $50 \mathrm{mg} / \mathrm{kg} /$ body weight of VC in one or few doses (oral or other) on a fixed schedule will not replicate the sufficiency seen in normal mammals. Mice and birds can synthesize considerable amounts of $\mathrm{VC},{ }^{16,17}$ but they can be still infected by avian influenza. Therefore, additional treatments other than ROS scavengers have been applied. For the avian-influenza-infected patient with pneumonia, continuous increase of alveolar/capillary membrane permeability is the most common damage. ${ }^{12}$ Mitochondria have a critical role in mediating calcium overload and oxidative damage (e.g., hydrogen peroxide)-induced cell death, such as ischemia reperfusion (IR) injury. ${ }^{18-20}$ The mitochondrial permeability transition (mPT) after this injury leads to mitochondrial swelling, outer membrane rupture and the release of apoptotic mediators (such as cytochrome $c$ ). ${ }^{18}$ The $\mathrm{mPT}$ pore is thought to consist of the adenine nucleotide translocator, a voltage-dependent anion channel and cyclophilin D. Cyclosporin A (CsA) can effectively inhibit cyclophilin $D$ and, therefore, it protects myocardial cells form IR injury (such as myocardial infarction). ${ }^{18} \mathrm{H} 1 \mathrm{~N} 1$ infection inactivated the cellular catalase, thus leading to the accumulation of ROS (mainly hydrogen peroxide), ${ }^{21}$ whereas $\mathrm{H} 5 \mathrm{~N} 1$ induced extracellular calcium influx, leading to apoptosis. ${ }^{22}$ ROS accumulation, extracellular calcium influx and the accompanying mitochondrial damages were also found in hypoxemia patient's lung cells. ${ }^{23}$ Thus, ROS accumulation (especially hydrogen peroxide) and calcium influx may be the common injury factors for both IR injuries and ARDS damages. CsA may have a protective effect on such damages caused by the avian influenza infection.
Clinical care of ARDS may result in IR injury of alveolar cells that are poorly ventilated or poorly supplied with blood. Avian-influenza-infected patients often develop the hypoxic pulmonary vasoconstriction (HPV), ${ }^{24}$ which is an essential physiological mechanism of the lung that directs blood perfusion from poorly ventilated to well-ventilated lung areas, to optimize gas exchange. But HPV development may cause mismatched blood flow and alveolar ventilation, and may result in life-threatening hypoxemia. ${ }^{23}$ Some ARDS clinical cares are usually carried out at this time, for example, mechanical ventilation, high-flow oxygen therapy, corticosteroid treatment and inhaled nitric oxide administration. ${ }^{23,24}$ However, these treatments may restore the blood (and oxygen) supply to the poorly ventilated or poorly supplied alveolar cells, where the damage similar to the IR injury may occur. Upon HPV, mechanical ventilation and high-flow oxygen therapy may restore the oxygen supply to the poorly ventilated alveolar cells. In case of a mismatch of blood flow and alveolar ventilation, corticosteroid treatment and inhaled nitric oxide administration may restore the blood supply to the poorly supplied but well-ventilated alveolar cells. For both the conditions, IR injury or similar damages may occur (Figure 2). In other words, more severe cell death may happen after the ARDS clinical management, but not at the time of occurrences of HPV or hypoxemia. CsA effectively inhibit this kind of damage and therefore may be the key drug for the survival of ARDS patients.

Nevertheless, CsA-treated cells are not protected from Bax (B-cell lymphoma 2 (Bcl-2)-associated $\mathrm{X}$ protein) or tumor necrosis factor- $\alpha$ (TNF $\alpha)$-induced mitochondrial dysfunction and cell death. ${ }^{18}$ Although $\mathrm{H} 5 \mathrm{~N} 1$ and $\mathrm{H} 1 \mathrm{~N} 1$ viruses dramatically induced the TNF $\alpha$ factor in alveolar macrophages, ${ }^{25-27}$ TNF activates both an apoptotic pathway (i.e., TRADD, RIP and $\mathrm{JNK}$ ) and a survival pathway mediated by $\mathrm{NF}-\kappa \mathrm{B}$ transcription of survival genes. ROS accumulation triggers a signal to facilitate the TNF $\alpha$ apoptotic pathway. ${ }^{28}$ Balance between the pro-apoptotic factor Bax and the anti-apoptotic members of the $\mathrm{Bcl}-2$ family is regulated by the cellular redox status. A tilt in favor of the superoxide abets cell survival and proliferation. On the contrary, a tilt towards hydrogen peroxide generates an intracellular milieu permissive of death execution. ${ }^{29}$ Thereby, a high dose of VC as an antioxidant (mainly scavenging hydrogen peroxide) may block both TNF- and Bax-induced apoptosis (Figure 3). Rapamycin regulates $\mathrm{Bcl}-2$ and $\mathrm{TNF} \alpha$ levels too, but it may exacerbate the H5N1-induced autophagy, which may lead to more severe cell death. ${ }^{30}$ Thus, Rapamycin may not be suitable for the treatment of AIV infection.

\section{Immunomodulators}

CsA also inhibits calcineurin activity. ${ }^{31}$ Calcineurin is a key enzyme in T-cell activation, which can stimulate the transcription of NF-AT (T-cell-specific transcription factor) and NF-IL-2A (IL-2 promoter elements). ${ }^{32}$ Thus, CsA blocks the activation of $T$ cells and suppresses the generation of a variety of cytokines, such as IL-2 and IFNs. ${ }^{32}$ CsA could not be replaced by FK506, because CsA works not only as an immunosuppressant (similar to $F K 506)^{31-33}$ but also as a 


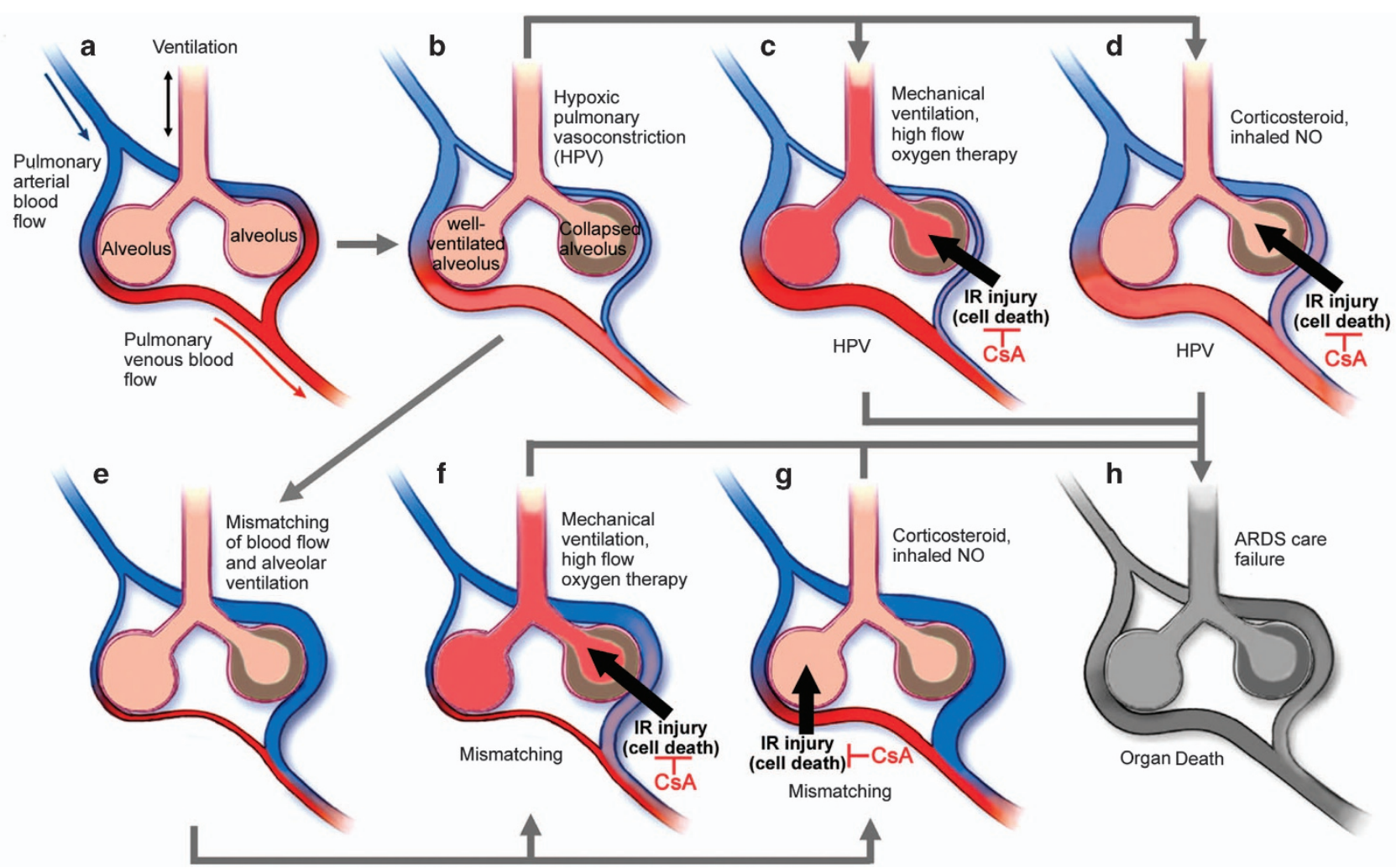

Figure 2 Possible IR injury during clinical care of ARDS. (a) Normal ventilation-perfusion matching. (b) HPV. (c) Upon HPV, mechanical ventilation and high-flow oxygen therapy may restore the oxygen supply to the poorly ventilated alveolar cells (with the possible occurrence of IR injury). (d) Corticosteroid treatment and inhaled NO administration may restore the blood supply to the poorly ventilated alveolar cells (with the possible occurrence of IR injury). (e) Mismatching of blood flow and alveolar ventilation results in hypoxemia. (f) Upon a mismatch, mechanical ventilation and high-flow oxygen therapy may restore the oxygen supply to the poorly ventilated alveolar cells (with the possible occurrence of IR injury). (g) Upon a mismatch, corticosteroid treatment and inhaled NO administration may restore the blood supply to the poorly supplied but well-ventilated alveolar cells (with the possible occurrence of IR injury). (h) Cell death may ultimately result in ARDS care failure and organ death. CsA may inhibit this IR injury and alveolar damages

protectant for maintaining the integrity of the mitochondrial membrane. ${ }^{18}$

Nevertheless, many side effects were found for CsA, for example, renal tubular toxicity and vascular-interstitial lesions. Thus, its substitutes (some small-molecule chemical compounds) have been developed recently, such as Debio-025 and GW5. ${ }^{34,35}$ However, none of them has been used clinically so far. CsA only shows its apparent side effects after a long-term use (usually over a year). ${ }^{36}$ Hence, for the current AIV therapy (usually within a month), CsA could be used expediently.

Szretter et al. ${ }^{37}$ showed that IFN $\alpha / \beta$ pretreatment significantly reduced the replication of the $\mathrm{H} 5 \mathrm{~N} 1$ virus. Zheng et al. ${ }^{26}$ indicated that combinations of immunomodulators and antiviral agents significantly reduced mortality in mice infected by a high inoculum of influenza H5N1 virus. They used two immunomodulators - Celecoxib (cyclooxygenase-2 inhibitor) and Mesalazine (5-amino salicylic acid). These two drugs did not cause significant immunosuppression and, hence, hardly influenced the body's immune system against AIV. ${ }^{26}$ Six of the eight cytokines induced by $\mathrm{H} 5 \mathrm{~N} 1$ and $\mathrm{H} 1 \mathrm{~N} 1$ (IL-6, IFN $\alpha$, macrophage inflammatory protein-1 $\beta$, IFN $\gamma$-induced protein 10, regulated on activation normal $\mathrm{T}$ cell expressed and secreted, and monocyte chemotactic protein 1) were suppressed by Celecoxib $(400 \mu \mathrm{g} / \mathrm{ml})$ and Mesalazine
$(200 \mu \mathrm{g} / \mathrm{ml}) .{ }^{27}$ Therefore, Celecoxib and Mesalazine may be two good candidate drugs that could suppress a cytokine 'storm,' besides CsA.

Some people may argue that CsA is a typical immunosuppressive agent and may weaken the body's resistance to AIV. However, considering that avian influenza causes an excessive immune response, it could be speculated that appropriately regulated immunity does not hamper the body's normal resistance to AIV. In fact, CsA affects influenza A virus M1 protein and inhibits the nuclear export of viral mRNA, and subsequently inhibits virus replication. ${ }^{38}$

Previous studies reported that acute lung injury caused by chemical or microbial insults was secondary to the generation of host-derived, oxidized phospholipid that could potently stimulate Toll-like receptor 4 (TLR4)-dependent inflammation. ${ }^{39} \mathrm{~A}$ recent study has shown that the TLR4 antagonist Eritoran protects mice from lethal influenza infection. ${ }^{40}$ Eritoran is an alternative immunomodulator (besides CsA, Celecoxib and Mesalazine, as mentioned above) for controlling the influenza-associated inflammation (Figure 3). Eritoran was originally designed as a drug for septicemia. The recent report showed that the survival rate of PR8 (a mouse-adapted influenza)-infected mice could reach $90 \%$ by the Eritoran treatment (if the mice were administered up to 6 days after influenza infection), ${ }^{40}$ indicating its strong 
immunomodulatory properties (may be stronger than all other immunomodulators). However, Eritoran has not been used formally clinically so far, and it has been observed that it may cause some notable side effect of a dose-dependent incidence of phlebitis. ${ }^{41}$ Similar to CsA, TLR4 also has a central role in IR injuries, ${ }^{42,43}$ which might suggest a similarity between AIV-induced inflammatory reactions and IRmediated immune responses.

\section{Protectant of Lysosome Integrity}

Neutrophil lysosomes contain a variety of neutral proteases and acid proteases. When neutrophils are activated or destroyed, lysosome lysis occurs and the proteases are released, causing surrounding protein degradation and increasing alveolar/capillary membrane permeability. ${ }^{44}$ Thus,

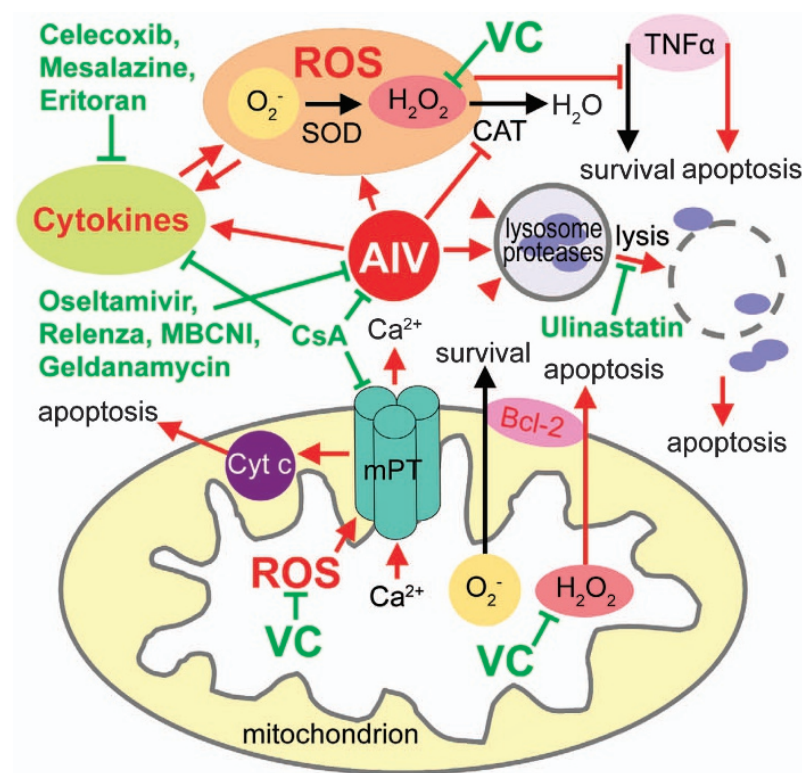

Figure 3 Model of the therapeutic mechanisms at the subcellular level. AIV-induced biochemical changes and cell death pathways are marked in red color. Potential targets of the drugs are marked in green color. AIV, avian influenza virus; Bcl-2, B-cell lymphoma 2; CAT, catalase; CsA, cyclosporin A; Cyt c, cytochrome $c$; $\mathrm{MBCNI}$, mechanism-based covalent neuraminidase inhibitors; $\mathrm{MPT}$, mitochondrial permeability transition; ROS, reactive oxygen species; SOD, superoxide dismutase; $\mathrm{TNF} \alpha$, tumor necrosis factor- $\alpha$; VC, vitamin $\mathrm{C}$ the elastase inhibitor has been considered for the AIV infection treatment, such as Sivelestat. ${ }^{44}$ However, Sivelestat is very expensive. The broad-spectrum protease inhibitor Ulinastatin, which also inhibits neutrophil elastase and lysosome lysis, may be used as an alternative selection. ${ }^{45,46}$ In H5N1-infected cells, the virus neuraminidase (NA) digests lysosomal membrane glycoproteins and affects lysosomal hydrolase, thereby undermining the integrity of the lysosome. ${ }^{47}$ Treatment with the protease inhibitor Ulinastatin could inhibit these destructive processes and could therefore be of potential importance to ARDS prevention and cure (Figure 3).

\section{Antiviral Drugs and the Others}

For AIV infection cure, suppression of viral replication or assembly has been adopted at the same time as well. ${ }^{48} \mathrm{NA}$ inhibitors, such as Oseltamivir and Relenza (or called Zanamivir), are usually the first choice for AIV inhibition. ${ }^{1,2,48}$ Besides them, the other two licensed M2 ion-channel inhibitors, amantadine and rimantadine, are also used. ${ }^{49,50}$ Another NA inhibitor, peramivir (BioCryst Pharmaceuticals, Durham, NC, USA), was in phase 3 trials in 2009 for both intravenous and intramuscular routes of administration. ${ }^{51}$ Another long-acting NA inhibitor, designated CS-8958, was under study for use by inhalation, in Japan. ${ }^{52}$ The viral polymerase inhibitor T-705 (Favipiravir) was not only active against all three types of influenza virus ( $A, B$ and $C)$ but also had some activity against other RNA viruses, including some of the hemorrhagic fever viruses. ${ }^{53,54}$ Sialidase fusion protein inhibitor DAS181 (Fludase) is a fusion construct that incorporates the sialidase from Actinomyces viscosus, a common oral bacterium linked to a human-epitheliumanchoring domain; it can be mass produced in Escherichia coli. ${ }^{55}$ The sialidase targets the viral attachment process, an early event in the replication of the influenza virus. ${ }^{55,56}$ Viral hemagglutinin inhibitors cyanovirin- $\mathrm{N}$ and thiazolides were also tested for $\mathrm{H} 1 \mathrm{~N} 1$ infection. ${ }^{57,58}$

Some new anti-influenza drugs have been developed recently, such as mechanism-based covalent NA inhibitors ${ }^{59}$ and Geldanamycin (an inhibitor of the viral polymerase assembly chaperone Hsp90). ${ }^{60,61}$ Moreover, combination therapy with currently available antivirals was supported by data from animal models and some clinical studies.

Table 1 Licensed drugs for curing AIV infection and the complications

\begin{tabular}{|c|c|c|c|}
\hline Drug names & Classification/mechanism & Suggested applied occasion & Possible side effects \\
\hline Vitamin C & Antioxidant & The whole course (of the infection) & $\begin{array}{l}\text { Diarrhea, nausea, vomiting and stomach cramps } \\
\text { (high dose) }\end{array}$ \\
\hline Cyclosporin A & $\begin{array}{l}\text { Mitochondrial permeability protectant and } \\
\text { immunosuppressant }\end{array}$ & $\begin{array}{l}\text { Middle and advanced stages with the pulmonary symptom } \\
\text { (may be especially useful after the ARDS care) }\end{array}$ & $\begin{array}{l}\text { Renal tubular toxicity and vascular-interstitial } \\
\text { lesions (only after long-term usage) }\end{array}$ \\
\hline Celecoxib & $\begin{array}{l}\text { Immunomodulator, cyclooxygenase-2 } \\
\text { inhibitor }\end{array}$ & The whole course & $\begin{array}{l}\text { Diarrhea, dyspepsia, headache, respiratory } \\
\text { infections, and so on }\end{array}$ \\
\hline Mesalazine & $\begin{array}{l}\text { Immunomodulator, cyclooxygenase and } \\
\text { lipoxygenase inhibitor }\end{array}$ & The whole course & Headache, flatulence, hair loss and itching \\
\hline Sivelestat & $\begin{array}{l}\text { Lysosome integrity protectant and } \\
\text { protease inhibitor }\end{array}$ & Middle and advanced stages with the pulmonary symptom & No side effect observed \\
\hline Ulinastatin & $\begin{array}{l}\text { Lysosome integrity protectant and } \\
\text { protease inhibitor }\end{array}$ & Middle and advanced stages with the pulmonary symptom & $\begin{array}{l}\text { Shock, itching, rash, nausea, vomiting or } \\
\text { neutropenia (usually after long-term usage) }\end{array}$ \\
\hline Oseltamivir & Antiviral drug, neuraminidase inhibitor & The whole course (especially effective at the early stage) & Rare: delirium, hallucinations or unusual behavior \\
\hline Relenza & Antiviral drug, neuraminidase inhibitor & The whole course (especially effective at the early stage) & Diarrhea, nausea, dizziness, fever and joint pain \\
\hline Amantadine & Antiviral drug, M2 ion-channel inhibitor & The whole course (especially effective at the early stage) & Hallucinations, difficulty breathing and seizures \\
\hline Rimantadine & Antiviral drug, M2 ion-channel inhibitor & The whole course (especially effective at the early stage) & Insomnia, dizziness, nervousness and nausea \\
\hline
\end{tabular}


The combinations may reduce the risk of development of resistant influenza virus strains. ${ }^{62,63}$

To alleviate ARDS, mechanical ventilation, high-flow oxygen therapy, inhaled nitric oxide administration, corticosteroid injection (although short-term high-dose glucocorticoids may cause necrosis of the femoral head) ${ }^{64}$ and other conventional approaches are also usually applied for critical patients. ${ }^{23,24,48,65,66}$ The various strategies used for ARDS care have been extensively reviewed elsewhere. ${ }^{65,66}$

\section{Conclusions and Perspective Clinical Trial}

AIV mutates vary rapidly and new viruses emerge constantly (H7N9 was possibly made from a combination of avian influenza A H9N2 and some other AIVs). ${ }^{2,10}$ Antiviral resistance mutations in specimens from patients with $\mathrm{H} 7 \mathrm{~N} 9$ infection have been reported recently. ${ }^{67}$ Thus, vaccine development will always be one step behind. Therefore, we should pay more attention to the responses of the human body rather than to the characters of the virus itself. If the excessive inflammatory response is restrained, AIV may be cleared later by the body's immune mechanism, as is the case of ordinary influenza.

In this review, five categories of drugs and therapeutic strategies for AIV infection have been summarized: (i) antioxidant (high-dose VC); (ii) mitochondrial permeability protectant and immunomodulators (CsA, with or without Celecoxib/Mesalazine or Eritoran); (iii) protease inhibitors (Ulinastatin); (iv) antiviral drugs (Oseltamivir/Relenza); and (v) clinical management of ARDS. Among them, licensed drugs are listed in Table 1. High doses of VC have been used for influenza treatments for a very long time; ${ }^{13-17}$ CsA has also been used to treat non-organ-transplantation-associated pneumonia; ${ }^{68}$ Celecoxib and Mesalazine (two prescription drugs) successfully cured mice infected with $\mathrm{H} 5 \mathrm{~N} 1 ; 26$ and Ulinastatin has a good curative effect on acute lung injury. ${ }^{45}$

Considering that they work on different cell death pathways, all four categories of drugs might ideally be used in a large combination to reduce the mortality rate. This therapeutic combination could be named 'avian influenza cocktail therapy' (AICT), similar to the cocktail therapy for HIV ${ }^{69}$ However, AICT may have additive or possible antagonistic effects on virus replication or induction of a cytokine storm. Moreover, the possible side effects of this new combination therapy have not been tested yet, although the treatment session should not be very long (usually $2-4$ weeks). Moreover, the dosage of the single compound should be adjusted according to the combination. For example, the blood concentration of CsA varies largely among individual patients and may be dramatically influenced by some other drugs. ${ }^{70-72}$ Therefore, careful pharmaceutical studies should be conducted before the AICT is made to really enter the clinical trial for human AIV infection.

The AICT and the individual drugs may also be effective to other high-mortality respiratory viral infections, besides avian influenza. It might be modified and then used for other disease therapies, such as SARS, neonatal respiratory distress syndrome and organ transplantation-associated viral pneumonia.

\section{Conflict of Interest}

The author declares no conflict of interest.
Acknowledgements. I thank Zi-Lin Li, MD, at the Fourth Military Medical University, China, and Zhong-Wei Zhang, PhD, and Zhong-Yi Zhao, PhD, at the Sichuan Agricultural University, China for their helpful discussions. This work was supported by the Support Program of Sichuan Agricultural University.

1. Gao HN, Lu HZ, Cao B, Du B, Shang H, Gan J-H et al. Clinical findings in 111 cases of influenza A (H7N9) virus infection. N Engl J Med 2013; 368: 2277-2285.

2. Gao R, Cao B, Hu Y, Feng Z, Wang D, Hu W et al. Human infection with a novel avian-origin influenza A (H7N9) virus. N Engl J Med 2013; 368: 1888-1897.

3. World Health Organization (WHO). Update 49 - SARS case fatality ratio, incubation period 2003. http://www.who.int/csr/sars/archive/2003_05_07a/en/.

4. World Health Organization (WHO). Epidemiology of WHO-confirmed human cases of avian A (H5N1) infection, 30 June 2006. Weekly Epidemiol Record 2006; 81: 249-260.

5. World Health Organization (WHO)The A/ 2009 H1N1 influenza virus pandemic 2009. http://www.who.int/vaccine_research/diseases/ari/en/index5.html.

6. Chan MCW, Cheung CY, Chui WH, Tsao SW, Nicholls JM, Chan YO et al. Proinflammatory cytokine responses induced by influenza A (H5N1) viruses in primary human alveolar and bronchial epithelial cells. Respir Res 2005; 6: 135.

7. Perrone LA, Plowden JK, Garcia-Sastre A, Katz JM, Tumpey TM. H5N1 and 1918 pandemic influenza virus infection results in early and excessive infiltration of macrophages and neutrophils in the lungs of mice. PLoS Pathog 2008; 4: e1000115.

8. Cilloniz C, Pantin-Jackwood MJ, Ni C, Goodman AG, Peng X, Projl SC et al. Lethal dissemination of $\mathrm{H} 5 \mathrm{~N} 1$ influenza virus is associated with dysregulation of inflammation and lipoxin signaling in a mouse model of infection. J Virol 2010; 84: 7613-7624.

9. Fukuyama S, Kawaoka Y. The pathogenesis of influenza virus infections: the contributions of virus and host factors. Curr Opin Immunol 2011; 23: 481-486.

10. Chen $Y$, Liang W, Yang S, Wu N, Gao H, Sheng J et al. Human infections with the emerging avian influenza A H7N9 virus from wet market poultry: clinical analysis and characterisation of viral genome. Lancet 2013; 381: 1916-1925.

11. Zhou J, Wang D, Gao R, Zhao B, Song J, Qi X et al. Biological features of novel avian influenza A (H7N9) virus. Nature 2013; 499: 500-503.

12. Tasaka S, Amaya F, Hashimoto S, Ishizaka A. Roles of oxidants and redox signaling in the pathogenesis of acute respiratory distress syndrome. Antioxid Redox Signal 2008; 10: 739-753.

13. Bland JS. Vitamin C: The Future is Now (Keats Good Health Guide). McGraw-Hill Press: Columbus, Ohio, USA, 1998. pp 1-48.

14. Pauling L. Vitamin C And The Common Cold. Freeman Press: San Francisco, California, USA, 1970.

15. Thorson A, Petzold M, Nguyen TK, Ekdahl K. Is exposure to sick or dead poultry associated with flulike illness?: a population-based study from a rural area in Vietnam with outbreaks of highly pathogenic avian influenza. Arch Intern Med 2006; 166: 119-123.

16. Ely JT. Ascorbic acid role in containment of the world avian flu pandemic. Exp Biol Med 2007; 232: 847-851.

17. Lewin S. Vitamin C: its Molecular Biology and Medical Potential. Academic Press: New York, New Jersey, USA, 1976.

18. Baines CP, Kaiser RA, Purcell NH, Blair NS, Osinska H, Hambleton MA et al. Loss of cyclophilin $\mathrm{D}$ reveals a critical role for mitochondrial permeability transition in cell death. Nature 2005; 434: 658-662.

19. Zhang ZW, Cheng J, Xu F, Yuan M, Du JB, Shang J et al. Mammal cells double their total RNAs against diabetes, ischemia reperfusion and malaria-induced oxidative stress. Mol Med 2011; 17: 533-541.

20. Zhang ZW, Cheng J, Xu F, Chen YE, Du JB, Yuan M et al. Red blood cell extrudes nucleus and mitochondria against oxidative stress. IUBMB Life 2011; 63: 560-565.

21. Yamada Y, Limmon GV, Zheng D, Li N, Li L, Yin L et al. Major shifts in the spatio-temporal distribution of lung antioxidant enzymes during influenza pneumonia. PLoS One 2012; 7: e31494.

22. Ueda M, Daidoji T, Du A, Yang CS, Ibrahim MS, Ikuta K et al. Highly pathogenic H5N1 avian influenza virus induces extracellular $\mathrm{Ca}^{2+}$ influx, leading to apoptosis in avian cells. $J$ Virol 2010; 84: 3068-3078.

23. Fuchs B, Sommer N, Dietrich A, Schermuly RT, Ghofrani HA, Grimminger F et al. Redox signaling and reactive oxygen species in hypoxic pulmonary vasoconstriction. Respir Physiol Neurobiol 2010; 174: 282-291.

24. Creagh-Brown BC, Griffiths MJD, Evans TW. Bench-to-bedside review: inhaled nitric oxide therapy in adults. Crit Care 2009; 13: 221.

25. Cheung CY, Poon LL, Lau AS, Luk W, Lau YL, Shortridge KF et al. Induction of proinflammatory cytokines in human macrophages by influenza $A(H 5 N 1)$ viruses: a mechanism for the unusual severity of human disease? Lancet 2002; 360: 1831-1837.

26. Zheng BJ, Chan KW, Lin YP, Zhao GY, Chan C, Zhang HJ et al. Delayed antiviral plus immunomodulator treatment still reduces mortality in mice infected by high inoculum of influenza A/H5N1 virus. Proc Natl Acad Sci USA 2008; 105: 8091-8096.

27. Woo PC, Tung ET, Chan KH, Lau CC, Lau SK, Yuen KY. Cytokine profiles induced by the novel swine-origin influenza $\mathrm{A} / \mathrm{H} 1 \mathrm{~N} 1$ virus: implications for treatment strategies. J Infect Dis 2010; 201: 346-353.

28. Han D, Ybanez MD, Ahmadi S, Yeh K, Kaplowitz N. Redox regulation of tumor necrosis factor signaling. Antioxid Redox Signal 2009; 11: 2245-2263. 
29. Low IC, Kang J, Pervaiz S. Bcl-2: a prime regulator of mitochondrial redox metabolism in cancer cells. Antioxid Redox Signal 2011; 15: 2975-2987.

30. Sun Y, Li C, Shu Y, Ju X, Zou Z, Wang H et al. Inhibition of autophagy ameliorates acute lung injury caused by avian influenza A H5N1 infection. Sci Signal 2012; 5: ra16.

31. Liu J, Farmer JD Jr, Lane WS, Friedman J, Weissman I, Schreiber SL. Calcineurin is a common target of cyclophilin-cyclosporin A and FKBP-FK506 complexes. Cell 1991; 66 : 807-815.

32. Frantz B, Nordby EC, Bren G, Steffan N, Paya CV, Kincaid RL et al. Calcineurin acts in synergy with PMA to inactivate I kappa B/MAD3, an inhibitor of NF-kappa B. EMBO J 1994; 13: $861-870$.

33. Grigoriu S, Bond R, Cossio P, Chen JA, Ly N, Hummer G et al. The molecular mechanism of substrate engagement and immunosuppressant inhibition of calcineurin. PLOS Bio 2013; 11: e1001492.

34. Millay DP, Sargent MA, Osinska H, Baines CP, Barton ER, Vuagniaux G et al. Genetic and pharmacologic inhibition of mitochondrial-dependent necrosis attenuates muscular dystrophy. Nat Med 2008; 14: 442-447.

35. Guo HX, Wang F, Yu KQ, Chen J, Bai DL, Chen KX et al. Novel cyclophilin D inhibitors derived from quinoxaline exhibit highly inhibitory activity against rat mitochondrial swelling and $\mathrm{Ca}^{2+}$ uptake/ release. Acta Pharmacol Sin 2005; 26: 1201-1211.

36. Dandel M, Lehmkuhl HB, Knosalla C, Hetzer R. Impact of different long-term maintenance immunosuppressive therapy strategies on patients' outcome after heart transplantation. Transpl Immunol 2010; 23: 93-103.

37. Szretter KJ, Gangappa S, Belser JA, Zeng H, Chen H, Matsuoka Y et al. Early control of H5N1 influenza virus replication by the type I interferon response in mice. J Virol 2009; 83 $5825-5834$.

38. Liu X, Zhao Z, Li Z, Xu C, Sun L, Chen J et al. Cyclosporin A inhibits the influenza virus replication through cyclophilin A-dependent and -independent pathways. PLoS One 2012 7: e37277.

39. Imai Y, Kuba K, Neely GG, Yaghubian-Malhami R, Perkmann T, van Loo G et al Identification of oxidative stress and Toll-like receptor 4 signaling as a key pathway of acute lung injury. Cell 2008; 133: 235-249.

40. Shirey KA, Lai W, Scott AJ, Lipsky M, Mistry P, Pletneva LM et al. The TLR4 antagonis Eritoran protects mice from lethal influenza infection. Nature 2013; 497: 498-502.

41. Barochia A, Solomon S, Cui X, Natanson C, Eichacker PQ. Eritoran tetrasodium (E5564) treatment for sepsis: review of preclinical and clinical studies. Expert Opin Drug Metab Toxicol 2011; 7: 479-494.

42. Shimamoto A, Pohlman TH, Shomura S, Tarukawa T, Takao M, Shimpo $H$ Toll-like receptor 4 mediates lung ischemia-reperfusion injury. Ann Thorac Surg 2006 82: 2017-2023.

43. Arumugam TV, Okun E, Tang SC, Thundyil J, Taylor SM, Woodruff TM. Toll-like receptors in ischemia-reperfusion injury. Shock 2009; 32: 4-16.

44. Iwata K, Doi A, Ohij G, Oka H, Oba Y, Takimoto K et al. Effect of neutrophil elastase inhibitor (sivelestat sodium) in the treatment of acute lung injury (ALI) and acute respiratory distress syndrome (ARDS): a systematic review and meta-analysis. Intern Med 2010; 49: 2423-2432.

45. Ito K, Mizutani A, Kira S, Mori M, Iwasaka H, Noguchi T. Effect of Ulinastatin, a human urinary trypsin inhibitor, on the oleic acid-induced acute lung injury in rats via the inhibition of activated leukocytes. Injury 2005; 36: 387-394.

46. Yamasaki F, Ishibashi M, Nakakuki M, Watanabe M, Shinkawa T, Mizota M. Protective action of ulinastatin against cisplatin nephrotoxicity in mice and its effect on the lysosomal fragility. Nephron 1996; 74: 158-167.

47. Ju XW. The Mechanism of Lysosome Depletion Induced by the Highly Pathogenic Avian Influenza Virus H5N1 Infection. PhD Dissertation of Peking Union Medical College: Beijing, China, 2012.

48. White NJ, Webster RG, Govorkova EA, Uyeki TM. What is the optimal therapy for patients with H5N1 influenza? PLoS Med 2009; 6: e1000091.

49. Nguyen JT, Hoopes JD, Smee DF, Prichard MN, Driebe EM, Engelhelthaler DM et al. Triple combination of oseltamivir, amantadine, and ribavirin displays synergistic activity against multiple influenza virus strains in vitro. Antimicrob Agents Chemother 2009; 53 : $4115-4126$.

50. Nguyen JT, Hoopes JD, Le MH, Smee DF, Patick AK et al. Triple combination of amantadine, ribavirin, and oseltamivir is highly active and synergistic against drug resistant influenza virus strains in vitro. PLoS One 2010; 5: e9332.

51. Yun NE, Linde NS, Zacks MA, Barr IG, Hurt AC, Smith JN et al. Injectable peramivi mitigates disease and promotes survival in ferrets and mice infected with the highly virulent influenza virus, A/Vietnam/1203/04 (H5N1). Virology 2008; 374: 198-209.
52. Macdonald SJF, Watson KG, Cameron R, Chalmers DK, Demaine DA, Fenton RJ et al. Potent and long-acting dimeric inhibitors of influenza virus neuraminidase are effective at once-weekly dosing regimen. Antimicrob Agents Chemother 2004; 48 : 4542-4549.

53. Furuta $\mathrm{Y}$, Takahashi K, Kuno-Maekawa M, Sangawa H, Uehara S, Kozaki K et al. Mechanism of action of T-705 against influenza virus. Antimicrob Agents Chemother 2005; 49: 981-986.

54. Sidwell RW, Barnard DL, Day CW, Smee DF, Bailey KW, Wong MH et al. Efficacy of orally administered T-705 on lethal avian influenza A(H5N1) virus infections in mice. Antimicrob Agents Chemother 2007; 51: 845-851.

55. Malakhov MP, Aschenbrenner LM, Smee DF, Wandersee MK, Sidwell RW, Gubareva LV et al. Sialidase fusion protein as a novel broad-spectrum inhibitor of influenza virus infection. Antimicrob Agents Chemother 2006; 50: 1470-1479.

56. Belser JA, Lu X, Szretter KJ, Jin X, Aschenbrenner LM, Lee A et al. DAS181, a nove sialidase fusion protein, protects mice from lethal avian influenza H5N1 virus infection. $J$ Infect Dis 2007; 196: 1493-1499.

57. Smee DF, Bailey KW, Wong MH, O'Keefe BR, Gustafson KR, Mishin VP et al. Treatment of influenza $A(\mathrm{H} 1 \mathrm{N1} 1)$ virus infections in mice and ferrets with cyanovirin-N. Antiviral Res 2008; 80: 266-271

58. Rossignol JF, La Frazia S, Chiappa L, Ciucci A, Santoro MG. Thiazolides, a new class of anti-influenza molecules targeting viral hemagglutinin at the post-translational level. J Biol Chem 2009; 284: 29798-29808.

59. Kim JH, Resende R, Wennekes T, Chen HM, Bance N, Buchini S et al. Mechanism-based covalent neuraminidase inhibitors with broad-spectrum influenza antiviral activity. Science 2013; 340: 71-75.

60. Chase G, Deng T, Fodor E, Leung BW, Mayer D, Schwemmle M et al. Hsp90 inhibitors reduce influenza virus replication in cell culture. Virology 2008; 377 : 431-439.

61. Liu PP, Hu Y, Zhao BH, Zhong F, He HX. Geldanamycin reduces proliferation of highly pathogenic H5N1 avian influenza virus in vivo. Chin Sci Bull 2013; 58: 1021-1026.

62. Hayden F. Developing new antiviral agents for influenza treatment: what does the future hold? Clin Infect Dis 2009; 48: S3-S13.

63. Boltz DA, Aldridge JR Jr, Webster RG, Govorkova EA. Drugs in development for influenza. Drugs 2010; 70: 1349-1362

64. Weinstein RS. Glucocorticoid-induced osteonecrosis. Endocrine 2012; 41: 183-190.

65. Demling RH. The modern version of adult respiratory distress syndrome. Annu Rev Med 1995; 46: 193-202.

66. Matthay MA, Ware LB, Zimmerman GA. The acute respiratory distress syndrome. J Clin Invest 2012; 122: 2731-2740.

67. Hu Y, Lu S, Song Z, Wang W, Hao P, Li J et al. Association between adverse clinical outcome in human disease caused by novel influenza A H7N9 virus and sustained viral shedding and emergence of antiviral resistance. Lancet 2013; 381: 2273-2279.

68. Koinuma D, Miki M, Ebina M, Tahara M, Hagiwara K, Kondo T et al. Successful treatment of a case with rapidly progressive Bronchiolitis obliterans organizing pneumonia (BOOP) using cyclosporin A and corticosteroid. Intern Med 2002; 41: 26-29.

69. Caliendo AM, Hirsch MS. Combination therapy for infection due to human immunodeficiency virus type 1. Clin Infect Dis 1994; 18: 516-524.

70. Levy GA. C2 monitoring strategy for optimising cyclosporin immunosuppression from the Neoral formulation. BioDrugs 2001; 15: 279-290.

71. Barbaro D, Orsini P, Pallini S, Piazza F, Pasquini C. Obesity in transplant patients: case report showing interference of orlistat with absorption of cyclosporine and review of literature. Endocr Pract 2002; 8: 124-126.

72. Federico S, Carrano R, Capone D, Gentile A, Palmiero G, Basile V. Pharmacokinetic interaction between levofloxacin and ciclosporin or tacrolimus in kidney transplant recipients: ciclosporin, tacrolimus and levofloxacin in renal transplantation. Clin Pharmacokinet 2006; 45: 169-175.

(1) (2) Cell Death and Disease is an open-access journal published by Nature Publishing Group. This work is licensed under a Creative Commons Attribution-NonCommercialShareAlike 3.0 Unported License. To view a copy of this license, visit http://creativecommons.org/licenses/by-nc-sa/3.0/ 